\title{
Superação da dormência de sementes de Cupressuslusitanica Mill
}

\section{Dormancybreak in seeds of Cupressuslusitanica Mill}

\author{
Sheila Ariana Xavier ${ }^{1 *}$; Josiane Fukami²; Lidiane Carla Vilanova Miotto ${ }^{3}$; \\ Renata Pinheiro Sobottka4; Suzana Heiko Nakatani ${ }^{5}$; \\ Lúcia Sadayo Assari Takahashi'; Maria Helena Machado ${ }^{6}$
}

\section{Resumo}

Cupressus lusitanica Mill. é uma das espécies florestais de alto potencial para utilização como quebraventos e produção de madeira no Brasil. Objetivando avaliar métodos de superação de dormência para promover a germinação de sementes de $C$. lusitanica foram testados os seguintes tratamentos: T1 (testemunha sem tratamento); T2 (imersão em água destilada por 24 horas); T3 (imersão em água destilada por 36 horas); T4 (estratificação úmida à $4{ }^{\circ} \mathrm{C}$ por 30 dias); T5 (imersão em água destilada por 8 horas + estratificação úmida à $4{ }^{\circ} \mathrm{C}$ por 30 dias); T6 (imersão em água destilada por 8 horas + estratificação úmida à $4{ }^{\circ} \mathrm{C}$ por 20 dias); T7 (imersão em água destilada por 12 horas + estratificação úmida à $4{ }^{\circ} \mathrm{C}$ por 20 dias); T8 (imersão em água destilada a $80^{\circ} \mathrm{C}$ por 5 minutos); T9 (imersão em $100 \mathrm{~mL}$ de ácido sulfúrico por 5 minutos). Avaliou-se a porcentagem de germinação e o índice de velocidade de germinação (IVG). Os resultados obtidos foram submetidos à análise de variância e as médias foram comparadas pelo Teste de Skott-knott. Os tratamentos T5, T2 e T7 proporcionaram maior germinação e o T7 maior velocidade de germinação, podendo estes serem recomendados para a superação da dormência de sementes de $C$. lusitanica.

Palavras-chave:Cipreste, estratificação, germinação e velocidade de germinação

\begin{abstract}
Cupressus lusitanica Mill. is a multipurpose tree species with a high potential for wood production in Brazil. The main objective was to evaluate methods to dormancy break to promote seed germinationin C. lusitanica. The following treatments were used: T1 (intact seeds); T2 (soaking in water for 24 hours); T3 (soaking in water for 36 hours); T4 (stratification on $4{ }^{\circ} \mathrm{C}$ for 30 days); T5 (immersion in water for 8 hours + stratification on $4{ }^{\circ} \mathrm{C}$ for 30 days); T6 (immersion in water for 8 hours + stratification on 4 ${ }^{\circ} \mathrm{C}$ for 20 days); $\mathrm{T} 7$ (immersion for 12 hours + stratification on $4{ }^{\circ} \mathrm{C}$ for 20 days); T8 (soaking in hot water at $80^{\circ} \mathrm{C}$ for 5 minutes); T9 (sulfuric acid soaking for 5 minutes). It was evaluated the percentage and germination speed (IVG). The resultsweresubmitted to ANOVA andmeanswere comparedusingthe Skott-Knott. The treatments T5, T2 and T7 showedhighergermination, and T7 higherspeedofgermination, thesecanberecommended for overcomingseeddormancyof C. lusitanica.

Key words: Cipreste, stratification, germination and germination speed
\end{abstract}

\footnotetext{
${ }^{1}$ Mestranda do Programa de Pós-Graduação em Fitopatologia, Universidade Estadual de Londrina, UEL, Londrina, PR. E-mail: sa_xavier@yahoo.com.br

${ }^{2}$ Mestranda do Programa de Pós-Graduação em Biotecnologia, UEL, Londrina, PR. E-mail: josifukami@hotmail.com

${ }^{3}$ Mestranda do Programa de Pós-Graduação em Fitotecnia, Universidade Federal de Lavras, UFLA, Lavras, MG. E-mail:lidianemiotto@hotmail.com

${ }^{4}$ Mestranda do Programa de Pós-Graduação em Ciências de Alimentos, UEL, Londrina, PR. E-mail: renatasobottka@yahoo.com.br

${ }^{5}$ Enga $^{\mathrm{a}}$ Agr ${ }^{\mathrm{a}}$, Sementes Mauá, Mauá da Serra, PR. E-mail: suzana_nakatani@hotmail.com

${ }^{6}$ Prof $^{\text {as. }}$ Dr $^{\text {ss }}$. do Dept ${ }^{\mathrm{o}}$ de Agronomia, UEL, Londrina, PR. E-mail:sadayo@uel.br; maria_helena@uel.br

* Autor para correspondência
} 
O cipreste (Cupressus lusitanica Mill.) é uma espécie conífera pertencente à família Cupressaceae, com origem nas regiões montanhosas do México, Guatemala, El Salvador e Honduras. É uma planta monóica, perenifólia, resinosa e aromática que pode atingir mais de $30 \mathrm{~m}$ de altura e até $1 \mathrm{~m}$ de diâmetro a $1,30 \mathrm{~m}$ do solo, popularmente conhecida como cipreste, cerca viva, cipreste lusitanica, cipreste de Portugal ou cipreste mexicano (CHAVES; FONSECA, 1991).

Dentre um grande número de espécies de Cupressus, a mais plantada no Brasil é C. lusitanica Mill., de origem mexicana com adaptação a uma ampla diversidade de condições ambientais. Esta espécie encontra-se na América Central, entre latitudes $15^{\circ} \mathrm{N}$ a $27^{\circ} \mathrm{N}$ e altitudes entre $2.200 \mathrm{~m}$ e 3.300m (CHAVES; FONSECA, 1991).

No Brasil, esta conífera tem sido utilizada, mais freqüentemente, para formar quebra-ventos e cercas vivas. Dado o grande porte que atinge com crescimento rápido e a característica compacta de suas copas, é comum o seu uso para formar abrigos e nas arborizações urbanas. Esta espécie é amplamente plantada, também, na Bolívia como quebra-ventos (SHIMIZU; PINTO JÚNIOR; RIBASKI, 1995). Além disso, pode ser manejada para a produção de madeira, inclusive nas pequenas propriedades rurais, visto que se adapta a vários tipos de solo.

As sementes de cedrinho são produzidas dentro de estruturas reprodutivas globosas denominadas cones, que amadurecem no outono. É importante coletar somente cones maduros (de coloração marrom) da última safra uma vez que cones velhos de várias safras passadas permanecem nos ramos por mais de 20 anos (GIANNINI; CAPUANA; GIOVANNELLI, 1999).

Após a coleta, os cones devem ser colocados para secar à sombra, em ambiente ventilado, até que suas escamas se abram e liberem as sementes. Estas são pequenas (230 mil sementes $\mathrm{kg}^{-1}$ ), aladas e mantêm a viabilidade por aproximadamente um ano se armazenadas em ambiente fresco e seco. Se forem mantidas em recipiente hermético, em câmara fria a $5^{\circ} \mathrm{C}$, sua viabilidade pode ser mantida por vários anos (SHIMIZU; PINTO JÚNIOR; RIBASKI, 1995).

A germinação tem início com a absorção de água pela semente e termina com o alongamento do eixo embrionário, em que a protrusão do embrião através do tegumento é o ponto crucial que identifica esse processo (BEWLEY; BLACK, 1994). Constituindo uma seqüência de eventos fisiológicosinfluenciada por fatores externos (ambientais: luz, temperatura, disponibilidadede água e de oxigênio) e internos (inibidores e promotores da germinação) àssementes, que podem atuar por si ou em interação com os demais. (NASSIF; VIEIRA; FERNADES, 1998).

A maioria das espécies perenes possui dificuldade de germinação, sendo necessários procedimentos para superar a dormência. Há uma carência de estudos de espécies arbóreas, nativas e exóticas (ARAÚJO et al., 2004), bem como de manejo das mesmas.

A dormência impede a germinação, mas é uma adaptação para a sobrevivência das espécies a longo prazo, pois geralmente faz com que as sementes mantenham-se viáveis por maior período de tempo, sendo superada em situações especiais. C. lusitanica possui porcentagem de germinação estimada entre 10 a $15 \%$ (SALAZAR-FIGUEROA; MORALESMORA; CARTÍN-BRENES, 1997) para aumentar sua porcentagem de germinação recomenda-se a superaçãode dormência com imersão em água por 24 a 48 horas, ou Estratificação úmida de 30 a 60 dias a $4^{\circ} \mathrm{C}$ (FLORIANO, 2004).

Diante do exposto, este trabalho objetivou avaliar diferentes métodos de superaçãode dormência para acelerar e uniformizar a germinação de sementes de C. lusitanica.

As sementes de C. lusitanica foram coletadas, no mês de abril de 2010, de oito árvores que apresentavam cones maduros, em uma área 
localizada a $23^{\circ} 23^{\prime} \mathrm{S}$ e $51^{\circ} 11^{\prime} \mathrm{W}$ e com latitude de $23^{\circ} 19^{\prime} 44^{\prime \prime} \mathrm{S}$ e longitude $51^{\circ} 12^{\prime} 10,23^{\prime \prime} \mathrm{O}$, no Centro de Ciências Agrárias (CCA), do Departamento de Agronomia, da Universidade Estadual de Londrina (UEL), em Londrina - PR. Após a coleta, procedeuse a secagem das sementes à sombra durante uma semana para posterior instalação do experimento, este foi conduzido no Laboratório de Fitotecnia desta mesma instituição.

O experimento foi realizado em delineamento inteiramente casualizado, com nove tratamentos e quatro repetições, com 100 sementes cada. Os tratamentosforam constituídos por: $\mathrm{T}_{1}$ - testemunha sem tratamento; $\mathrm{T}_{2}$ - imersão em $100 \mathrm{~mL}$ de água destilada à temperatura ambiente por 24 horas; $\mathrm{T}_{3}$ imersão em $100 \mathrm{~mL}$ de água destilada à temperatura ambiente por 36 horas; $\mathrm{T}_{4}$-estratificação úmida à $4{ }^{\circ} \mathrm{C}$ por 30 dias; $\mathrm{T}_{5}$ - imersão em $100 \mathrm{~mL}$ de água destilada à temperatura ambiente por 8 horas + estratificação úmida à $4{ }^{\circ} \mathrm{C}$ por 30 dias; $\mathrm{T}_{6}$ - imersão em $100 \mathrm{~mL}$ de água destilada à temperatura ambiente por 8 horas + estratificação úmida à $4{ }^{\circ} \mathrm{C}$ por 20 dias; $\mathrm{T}_{7}$ - imersão em $100 \mathrm{~mL}$ de água destilada à temperatura ambiente por 12 horas + estratificação úmida à $4{ }^{\circ} \mathrm{C}$ por 20 dias; $\mathrm{T}_{8}$ - imersão em $100 \mathrm{~mL}$ de água destilada a $80^{\circ} \mathrm{C}$ por 5 minutos e; $\mathrm{T}_{9}$ - imersão em ácido sulfúrico por 5 minutos.

Os métodos utilizados para a superação da dormência foram:

Estratificação a frio: Utilizou-se areia bem lavada que apresentava grãos em torno de 2,0 $\mathrm{mm}$ de diâmetro (média) para facilitar a posterior separação das sementes por peneiragem. O recipiente em que foi colocado o meio, permitiu boa drenagem evitando-se a acumulação de água no fundo para não causar o apodrecimento das sementes. A temperatura para a estratificação a frio utilizada foi de $4^{\circ} \mathrm{C}$. As sementes foram colocadas entre duas camadas de areia com $5 \mathrm{~cm}$ de espessura. O período de estratificação foi de 20 e 30 dias, de acordo com cada tratamento. Uma vez encerrado o período de estratificação, as sementes foram semeadas imediatamente, para evitar a indução de dormência secundária.
Imersão em água quente: a água foi aquecida até a temperatura de $80^{\circ} \mathrm{C}$, as sementes foram imersas, permanecendo por um período de 5 minutos, e depois foram colocadas para germinar;

Escarificação ácida: as sementes foram imersas em ácido sulfúrico por um período de 5 minutos, após esse período as sementes foram lavadas em água corrente e colocadas para germinar.

Após tratadas, as sementes foram dispostas em gerbox com papel mata-borrão umedecido, previamente esterilizado, e acondicionadas em câmara de germinação, tipo BOD, com temperatura de $20^{\circ} \mathrm{C}$ por 21 dias (BRASIL, 2009).

A germinação foi avaliada semanalmente por meio da porcentagem de plântulas normais e foi considerada germinada as sementes que iniciaram o processo de emissão das estruturas essenciais do embrião.

O índice de velocidade de germinação (IVG) foi calculado pela fórmula proposta por Maguire (1962): $\mathrm{IVG}=\mathrm{G}_{1} / \mathrm{N}_{1}+\mathrm{G}_{2} / \mathrm{N}_{2}+\ldots+\mathrm{Gn} / \mathrm{Nn}$ onde: $\mathrm{G}_{1}, \mathrm{G}_{2}, \mathrm{Gn}=$ número de plântulas germinadas na primeira, segunda, até a última contagem e $\mathrm{N}_{1}, \mathrm{~N}_{2}$, $\mathrm{Nn}=$ número de semanas desde a primeira, segunda, até a última contagem.

Os resultados obtidos, foram submetidos a teste de separação de médias, Scott-Knott ao nível de 5\% de probabilidade, utilizando-se o software SASMAgri (CANTERI et al., 2001), transformando os dados originais em "arcsen $\sqrt{x}_{\mathrm{x}} / 100$ ".

Os resultados obtidos para porcentagem de germinação e índice de velocidade de germinação estão apresentados na tabela 1.Os tratamentos que apresentaram as maiores porcentagens de germinação para C. lusitânica, foram $\mathrm{T}_{2}$ (imersão em $100 \mathrm{~mL}$ de água destilada à temperatura ambiente por 24 horas), $\mathrm{T}_{5}$ (imersão em $100 \mathrm{~mL}$ de água destilada à temperatura ambiente por 8 horas + estratificação úmida à $4{ }^{\circ} \mathrm{C}$ por 30 dias) e $\mathrm{T}_{7}$ (imersão em $100 \mathrm{~mL}$ de água destilada à temperatura ambiente por 12 horas + estratificação úmida à $4{ }^{\circ} \mathrm{C}$ por 20 dias), sendo estes estatisticamente superiores aos demais tratamentos. 
Tabela 1. Germinação e índice de velocidade de germinação de Cupressus lusitanica. Londrina, PR. 2010.

\begin{tabular}{lcccc}
\hline Trat. & \multicolumn{2}{c}{$\begin{array}{c}\text { Germinação } \\
(\%)\end{array}$} & \multicolumn{2}{c}{$\begin{array}{c}\text { Índice de Velocidade } \\
\text { de Germinação }\end{array}$} \\
\hline Trat. 01 & \multicolumn{2}{c}{ * } & 3,00 & $\mathrm{C}$ \\
Trat. 02 & 89,50 & $\mathrm{~B}$ & 6,39 & $\mathrm{~B}$ \\
Trat. 03 & 56,00 & $\mathrm{~B}$ & 3,98 & $\mathrm{C}$ \\
Trat. 04 & 47,25 & $\mathrm{~B}$ & 3,18 & $\mathrm{C}$ \\
Trat. 05 & 77,00 & $\mathrm{~A}$ & 6,90 & $\mathrm{~B}$ \\
Trat. 06 & 59,75 & $\mathrm{~B}$ & 8,01 & $\mathrm{~B}$ \\
Trat. 07 & 90,00 & $\mathrm{~A}$ & 12,21 & $\mathrm{~A}$ \\
Trat. 08 & 0,00 & $\mathrm{D}$ & 0,00 & $\mathrm{D}$ \\
Trat. 09 & 26,00 & $\mathrm{C}$ & 1,33 & $\mathrm{D}$ \\
\hline CV & $25,07 \%$ & & $24,10 \%$ & \\
\hline
\end{tabular}

Médias seguidas de mesma letra na coluna não diferem estatisticamente entre si pelo teste de Scott-Knott ao nível de 5\%.Dados transformados em " $\operatorname{arcsen}\left((\mathrm{x} / 100)^{\wedge} 1 / 2\right) "$.

$* \mathrm{~T}_{1}$ - testemunha sem tratamento;

$\mathrm{T}_{2}$ - imersão em $100 \mathrm{~mL}$ de água destilada à temperatura ambiente por 24 horas;

$\mathrm{T}_{3}$ - imersão em $100 \mathrm{~mL}$ de água destilada à temperatura ambiente por 36 horas;

$\mathrm{T}_{4}$-estratificação úmida à $4{ }^{\circ} \mathrm{C}$ por 30 dias;

$\mathrm{T}_{5}$ - imersão em $100 \mathrm{~mL}$ de água destilada à temperatura ambiente por 8 horas + estratificação úmida à $4{ }^{\circ} \mathrm{C}$ por 30 dias;

$\mathrm{T}_{6}$ - imersão em $100 \mathrm{~mL}$ de água destilada à temperatura ambiente por 8 horas + estratificação úmidaà $4{ }^{\circ} \mathrm{C}$ por 20 dias;

$\mathrm{T}_{7}$ - imersão em $100 \mathrm{~mL}$ de água destilada à temperatura ambiente por 12 horas + estratificação úmida à $4{ }^{\circ} \mathrm{C}$ por 20 dias;

$\mathrm{T}_{8}$ - imersão em $100 \mathrm{~mL}$ de água destiladaa $80^{\circ} \mathrm{C}$ por 5 minutos e;

$\mathrm{T}_{9}$ - imersão em ácido sulfúrico por 5 minutos.

Fonte: Elaboração dos autores.

Os resultados obtidos são semelhantes ao observados por Bianchetti (1989), que recomendou a imersão em $100 \mathrm{~mL}$ de água destilada por 24 a 48 horas ou estratificação úmida à $4{ }^{\circ} \mathrm{C}$ por 30 a 60 dias para superar a dormência das sementes. No entanto, observa-se que os tratamentos $\mathrm{T}_{3}$ (imersão em 100 $\mathrm{mL}$ de água destilada à temperatura ambiente por 36 horas) e $\mathrm{T}_{4}$ (estratificação úmida à $4{ }^{\circ} \mathrm{C}$ por 30 dias) não foram eficientes para obter resultados superiores a testemunha (Tabela 1). De acordo com os dados apresentados, observa-se que desde que seja realizada a combinação de métodos como, imersão em $100 \mathrm{~mL}$ de água destilada + estratificação úmida a $4^{\circ} \mathrm{C}$, não houve a necessidade de esperar 30 a 60 dias para obter a superação de dormência como sugere Bianchetti (1989), fato confirmado pelos valores encontrados no $\mathrm{T}_{7}$ (imersão em $100 \mathrm{~mL}$ de água destilada à temperatura ambiente por 12 horas + estratificação úmida à $4{ }^{\circ} \mathrm{C}$ por 20 dias).

Observa-se que no $\mathrm{T}_{8}$ (imersão em $100 \mathrm{~mL}$ de água destilada a $80^{\circ} \mathrm{C}$ por 5 minutos), a germinação das sementes foi nula, podendo considerar assim que este tratamento causou a morte do embrião das sementes. $\mathrm{O} \mathrm{T}_{9}$ (imersão em ácido sulfúrico por 5 minutos), também não apresentou resultados satisfatórios, obtendo porcentagem de germinação inferior a testemunha.

Grus, De Matte e Graziano (1984), testando alguns tratamentos de superação de dormência para as sementes de Caesalpinia leiostachya (Benth.), Ducke (pau-ferro) e Cassia javanica Ried (cássia javanesa), também, constataram que os tratamentos de imersão em água fervente durante um, dois, três, quatro e cinco minutos foram prejudiciais às sementes, matando ou danificando o embrião. Borges et al. (1982) constataram que o tratamento de imersão de sementes de Copaifera langsdorffii Desf. (copaíba) à temperatura de $80^{\circ} \mathrm{C}$ foi pouco eficiente, superando apenas a testemunha. Para C. arizonica, a recomendação para superação de dormência é realizar o pré-esfriamento de 3 a $5{ }^{\circ} \mathrm{C}$ por 21 dias. 
A análise do índice de velocidade de germinação (IVG) permite evidenciar melhor as diferenças entre os tratamentos (Tabela 1). O $\mathrm{T}_{7}$ (imersão em $100 \mathrm{~mL}$ de água destilada em temperatura ambiente por 12 horas + estratificação úmida à 4 ${ }^{\circ} \mathrm{C}$ por 20 dias), apresentou maior valor de IVG, sendo significativamente superior aos demais tratamentos, seguido dos $\mathrm{T}_{2}$ (imersão em $100 \mathrm{~mL}$ de água destilada à temperatura ambiente por 24 horas), $\mathrm{T}_{5}$ (imersão em $100 \mathrm{~mL}$ de água destilada à temperatura ambiente por 8 horas + estratificação úmida à $4{ }^{\circ} \mathrm{C}$ por 30 dias) e $\mathrm{T}_{6}$ (imersão em 100 $\mathrm{mL}$ de água destilada à temperatura ambiente por 8 horas + estratificação úmida à $4{ }^{\circ} \mathrm{C}$ por 20 dias), que apresentaram resultados estatisticamente superiores à testemunha.
Verificou-se também diferença da porcentagem de germinação de sementes durante os períodos avaliados de 7, 14 e 21 dias (Tabela 2), indicando que alguns tratamentos aceleram a germinação de cipreste. Com a aplicação dos tratamentos $T_{5}$ (imersão em $100 \mathrm{~mL}$ de água destilada à temperatura ambiente por 8 horas + estratificação úmida à $4{ }^{\circ} \mathrm{C}$ por 30 dias), $\mathrm{T}_{6}$ (imersão em $100 \mathrm{~mL}$ de água destilada à temperatura ambiente por 8 horas + estratificação úmida à $4{ }^{\circ} \mathrm{C}$ por 20 dias)e $\mathrm{T}_{7}$ (imersão em $100 \mathrm{~mL}$ de água destilada à temperatura ambiente por 12 horas + estratificação úmida à $4{ }^{\circ} \mathrm{C}$ por 20 dias), foi possível obter germinação já na primeira avaliação aos sete dias, enquanto que nos demais tratamentos, inclusive a testemunha, não houve germinação nesta primeira contagem.

Tabela 2. Germinação de sementes de Cupressus lusitanica ao sétimo, décimo quarto e vigésimo primeiro dia após a montagem do experimento (DAM). Londrina, PR. 2010.

\begin{tabular}{ccccccc}
\hline Trat. & $7^{\circ}$ DAM $(\%)$ & $14^{\circ}$ DAM $(\%)$ & \multicolumn{2}{c}{$21^{\circ}$ DAM $(\%)$} \\
\hline Trat. 01 & 0,00 & d & 46,75 & $\mathrm{~b}$ & 0,25 & $\mathrm{c}$ \\
Trat. 02 & 0,00 & $\mathrm{~d}$ & 89,50 & $\mathrm{a}$ & 0,00 & $\mathrm{c}$ \\
Trat. 03 & 0,00 & $\mathrm{~d}$ & 55,25 & $\mathrm{~b}$ & 0,75 & $\mathrm{c}$ \\
Trat. 04 & 0,00 & $\mathrm{~d}$ & 39,25 & $\mathrm{~b}$ & 8,00 & $\mathrm{~b}$ \\
Trat. 05 & 30,50 & $\mathrm{c}$ & 13,75 & $\mathrm{c}$ & 32,75 & $\mathrm{a}$ \\
Trat. 06 & 53,00 & $\mathrm{~b}$ & 4,75 & $\mathrm{c}$ & 2,00 & $\mathrm{c}$ \\
Trat. 07 & 81,00 & $\mathrm{a}$ & 9,00 & $\mathrm{c}$ & 0,00 & $\mathrm{c}$ \\
Trat. 08 & 0,00 & $\mathrm{~d}$ & 0,00 & $\mathrm{~d}$ & 0,00 & $\mathrm{c}$ \\
Trat. 09 & 0,00 & $\mathrm{~d}$ & 3,75 & $\mathrm{c}$ & 22,25 & $\mathrm{a}$ \\
\hline
\end{tabular}

Médias seguidas de mesma letra na coluna não diferem estatisticamente entre si pelo teste de Scott-Knott ao nível de 5\%.Dados transformados em " $\operatorname{arcsen}\left((\mathrm{x} / 100)^{\wedge} 1 / 2\right) "$.

Fonte: Elaboração dos autores.

A temperatura da água de embebição em que a semente está germinando exerce efeito considerável sobre o processo. Temperaturas abaixo da ótima tendem a reduzir a velocidade do processo de germinação (CARVALHO; NAKAGAWA, 2000). Burch e Delouche (1959), trabalhando com quatro espécies, verificaram que, na temperatura de $30{ }^{\circ} \mathrm{C}$, os teores de água (\%) absorvidos são maiores que a $20{ }^{\circ} \mathrm{C}$, como no presente trabalho a temperatura utilizada foi a mesma para todos os tratamentos o que pode ter causado o diferença no teor de embebição foi o tempo em que as sementes ficaram embebidas.

Possível observar que os tratamentos obtiveram os maiores valores de germinação foram $\mathrm{T}_{2}, \mathrm{~T}_{5} \mathrm{e}$ $\mathrm{T}_{7}$ e que o inicio da germinação ocorreu em dias diferentes. As sementes de cipreste iniciaram a germinação antes do $7^{\circ}$ DAM para $0 \mathrm{~T}_{7}$, entre $\mathrm{o}$ $7^{\circ}$ e o $14^{\circ}$ DAM para o tratamento $\mathrm{T}_{2}$ e depois do $14^{\circ}$ DAM para o tratamento $\mathrm{T}_{5}$. No entanto, $\mathrm{T} 2$ apresentou porcentagem de germinação total das 
sementes satisfatório, tendo uma metodologia mais simples, necessitando de um período de superação de dormência menor (24 horas) comparado aos demais tratamentos, com IVG entre 7 a 14 dias.

Observa-se que o $\mathrm{T}_{9}$ (imersão em ácido sulfúrico por 5 minutos), também teve inicio da germinação após $14^{\circ}$ DAM, no entanto obteve índices de germinação total inferior a testemunha (Tabela 2). Eira et al., trabalhando com sementes de Enterolobium contortisiliquum também obteve em seu experimento plântulas normais após o décimo quarto dia porém os resultados dos tratamentos com ácido sulfúrico foram superiores que o apresentado pela testemunha.

Os tratamentos T5, T2 e T7 proporcionaram maior germinação e o T7 maior velocidade de germinação, podendo estes serem recomendados para a superação da dormência de sementes de $C$. lusitanica.

\section{Referências}

ARAÚJO, E. C.; MENDONÇA, A. V. R.; BARROSO, D. G.; LAMÔNICA, K. R.; SILVA, R. F.Caracterização morfológica de frutos, sementes e plântulas de Sesbaniavirgata (Cav.) Pers. Revista Brasileira de Sementes, Pelotas, v. 26, n. 1, p. 104-109, 2004.

BEWLEY, J. D.; BLACK, M. Seeds: physiology of development and germination. 2. ed. New York: Plenum, 1994. $445 \mathrm{p}$.

BIANCHETTI, A. Tratamentos pré-germinativos para sementes florestais. In: SIMPÓSIO BRASILEIRO SOBRE TECNOLOGIADE SEMENTES FLORESTAIS, 2., São Paulo, 1989. Anais... São Paulo: Instituto Florestal, 1991. p. 237-247. (Série Documentos).

BORGES, E. E. L.; BORGES, R. C. G.; CANDIDO, J. F.; GOMES, J. M. Comparação de métodos de quegra de dormência em sementes de copaíba. Revista Brasileira de Sementes, Brasília, v. 4, n. 1, p. 9-12, 1982.

BRASIL. Ministério da Agricultura, Pecuária e Abastecimento. Regras para análises de sementes. Brasília: Secretaria de Defesa Agropecuária, 2009. 395 p.

BURCH, A.; DELOUCHE, J. C. Absorption of water by seeds. Proceedings of the Association Official Seeds Analyst, Oklahoma City, v. 49, p. 142-150, 1959.
CANTERI, M. G.; ALTHAUS, R. A.; VIRGENS FILHO, J. S.; GIGLIOTI, E. A.; GODOY, C. V. SASM - Agri: sistema para análise e separação de médias em experimentos agrícolas pelos métodos Scott-Knott, Tukey e Duncan. Revista Brasileira de Agrocomputação, Londrina, v. 1, n. 2, p. 18-24, 2001.

CARVALHO, N. M.; NAKAGAWA, J. Sementes: ciência, tecnologia e produção. Jaboticabal: FUNEP, 2000. 588 p.

CHAVES, E.; FONSECA, W. Cipres: Cupressuslusitanica Mill. Espécie de arbol de uso multipleen America Central. Turrialba: CATIE, 1991. 66 p. (CATIE, Série Técnica, Informe Técnico, 168).

FLORIANO, E. P. Germinação e dormência de sementes florestais. Santa Rosa: ANORGS, 2004. 91 p. (Caderno Didático, n. 2).

GIANNINI, R.; CAPUANA, M.; GIOVANNELLI, A. Raising plant material. In: TEISSIER DU CROS, E.; DUCREY, M.; BARTHELEMY, D.; PICHOT, C.; GIANNINI, R.; RADDI, P.; ROQUES, A.; SALES L. J.; THIBAUT, B. (Ed.). Cypress: a practicalhandbook. Florence: Studio Leonardo, 1999. p. 45-54.

GRUS, V. M.; DE MATTE, M. E. S. P.; GRAZIANO, T. T. Germinação de sementes de pau-ferro e cássiajavanesa submetidas a tratamentos para quebra de dormência. Revista Brasileira de Sementes, Brasília, v. 6 , n. 2, p. 29-35, 1984.

MAGUIRE, J. D. Speed of germination - aid in selection and evaluation for seedling emergence and vigor. Crop Science, Madison, v. 2, p. 176-177, 1962.

NASSIF, S. M. L.; VIEIRA, I. G.; FERNADES, G. D. (LARGEA/). Fatores externos (ambientais) que influenciam na germinação de sementes. Piracicaba: IPEF/LCF/ESALQ/USP, 1998. Disponível em: <http:// www.ipef.br/sementes/>. Acesso em: 20 nov. 2011.

SALAZAR-FIGUEROA, R.; MORALES-MORA, E.; CARTÍN-BRENES, F. (Ed.). Estado del mejoramiento genético y laproducción de semillasforestalesen Costa Rica. In: CONGRESO FORESTAL NACIONAL: UNIDOS POR EL DESARROLLO DEL RECURSO FORESTAL: ANTE EL PRÓXIMO MILENIO, 3., 1997, San José. Conferência... MINAE, CR: San José, 1997. p. 64-71.

SHIMIZU, J. Y.; PINTO JÚNIOR, J. E.; RIBASKI, G. Cipreste para madeira: alto incremento volumétrico com material genético apropriado. Boletim de Pesquisa Florestal, Colombo, n. 30-31, p. 3-17, jan./dez. 1995. 